International Journal of Environmental Research and

Article

\title{
Smoking Cessation among Low-Socioeconomic Status and Disadvantaged Population Groups: A Systematic Review of Research Output
}

\section{Ryan J. Courtney ${ }^{1, *}$, Sundresan Naicker ${ }^{1}$, Anthony Shakeshaft ${ }^{1}$, Philip Clare 1, Kristy A. Martire ${ }^{1,2}$ and Richard P. Mattick ${ }^{1}$}

1 National Drug and Alcohol Research Centre (NDARC), University of New South Wales, Sydney, NSW 2052, Australia; E-Mails: s.naicker@unsw.edu.au (S.N.); a.shakeshaft@unsw.edu.au (A.S.); p.clare@unsw.edu.au (P.C.); k.martire@unsw.edu.au (K.A.M.); r.mattick@unsw.edu.au (R.P.M.)

2 School of Psychology, University of New South Wales, Sydney, NSW 2052, Australia

* Author to whom correspondence should be addressed; E-Mail: r.courtney@unsw.edu.au; Tel.: +61-(2)-8936-1004; Fax: +61-(2)-9385-0222.

Academic Editors: Coral Gartner and Britta Wigginton

Received: 29 April 2015 / Accepted: 3 June 2015 / Published: 8 June 2015

\begin{abstract}
Background: Smoking cessation research output should move beyond descriptive research of the health problem to testing interventions that can provide causal data and effective evidence-based solutions. This review examined the number and type of published smoking cessation studies conducted in low-socioeconomic status (low-SES) and disadvantaged population groups. Methods: A systematic database search was conducted for two time periods: 2000-2004 (TP1) and 2008-2012 (TP2). Publications that examined smoking cessation in a low-SES or disadvantaged population were coded by: population of interest; study type (reviews, non-data based publications, data-based publications (descriptive, measurement and intervention research); and country. Intervention studies were coded in accordance with the Cochrane Effective Practice and Organisation of Care data collection checklist and use of biochemical verification of self-reported abstinence was assessed. Results: 278 citations were included. Research output (i.e., all study types) had increased from TP1 $27 \%$ to TP2 $73 \%\left(\chi^{2}=73.13\right.$, $p<0.001$ ), however, the proportion of data-based research had not significantly increased from TP1 and TP2: descriptive (TP1 $=23 \%$ vs. TP2 $=33 \%)$ or intervention $(\mathrm{TP} 1=77 \%$ $v s . \mathrm{TP} 2=67 \%)$. The proportion of intervention studies adopting biochemical verification
\end{abstract}


of self-reported abstinence had significantly decreased from TP1 to TP2 with an increased reliance on self-reported abstinence $(\mathrm{TP} 1=12 \%$ vs. TP2 $=36 \%)$. Conclusions: The current research output is not ideal or optimal to decrease smoking rates. Research institutions, scholars and funding organisations should take heed to review findings when developing future research and policy.

Keywords: smoking cessation; social class; socio-economic factors; poverty; review; intervention; homeless persons; indigenous population; mental disorders; prisoners

\section{Introduction}

Smoking rates have declined in most developed countries [1,2], but inequalities in smoking rates have persisted, or increased, over time [3-6]. Data collected from the Global Tobacco Surveillance System [7], the World Health Organisation (WHO) STEPwise approach to surveillance (STEPS) program [8] and Health Surveys [9] have demonstrated that the frequency, quantity and modes of tobacco smoking are not equally distributed within or across countries or population groups. The cumulative prevalence of tobacco consumption is often highest among those with low educational attainment and lower income levels [10]. The smoking rate among individuals with a mental illness is nearly twice that of adults without mental illness [11]. Similarly for other disadvantaged population groups smoking rates are markedly higher compared to the general population, e.g., homeless persons 70 percent [12,13], Indigenous persons 50 percent [14,15], and prisoners between 50 to 83 percent [16].

Reducing smoking rates among low-socioeconomic status (low-SES) and disadvantaged groups is critical to improving life expectancy and reducing health inequalities [17]. Using indirect estimation techniques to attribute mortality caused by smoking across four countries (Australia, UK, Canada, and the US), smoking accounts for nearly half of excess mortality among men aged 35-69 years within the lowest SES stratum [18]. In the UK, over half of the difference in survival to age 70 years between the highest and lowest social classes is attributable to the higher smoking prevalence in the lowest socioeconomic quintile [17,19]. The economic costs of smoking are high among low-SES and disadvantaged groups. Most recent estimates using the WHO's Economics of Tobacco Toolkit indicate that the economic cost of smoking for people with mental illness in the UK was $£ 2.34$ billion from 2009 to 2010 [20]. This high cost and burden of disease attributable to tobacco smoking has led to calls for the "development and implementation of smoking cessation interventions" to be a "high economic and clinical priority" among low-SES and disadvantaged population groups, particularly smokers with mental disorders [20].

Tobacco consumption is a well-elucidated modifiable risk factor and its cessation may significantly reduce both the absolute and relative risk of disease burden and mortality across all population groups.

Tobacco surveillance activities have provided useful information on the implementation of tobacco control efforts and World Health Surveys have identified complex patterns of tobacco use and social determinants of smoking [10]. However, to improve our global knowledge base, it is important that appropriate interventions are targeted, implemented and evaluated. The WHO Framework Convention on Tobacco Control (WHO FCTC) was ratified in 2005 by 168 WHO members states and has 
identified as a key priority the need for signatory countries to: "design and implement effective programmes aimed at promoting the cessation of tobacco use" [21,22]. All countries included in this review (at the exception of two countries i.e., China and Taiwan) were signatories to the WHO FCTC, which aims to implement an internationally coordinated strategy to both reduce the uptake and increase cessation. Disparities in smoking prevalence highlight the need for strategies to address both smoking initiation and increasing smoking cessation among low-SES and disadvantaged groups [23]. The focus of this review is to reach a critical endpoint of identifying research output related to smoking cessation among low-SES and disadvantaged groups.

Two consistently used measures to quantify the contribution of research applied to other health-related fields are: the number of publications, and the type of research design (e.g., measurement, descriptive, intervention and evaluation of intervention effects) [24,25]. For the purpose of this review, these same measures were used in order to systematically quantify and evaluate smoking cessation research output regarding low-SES and disadvantaged groups.

This review will examine research output across countries to identify any differences in patterns of research output across countries, or in particular whether some countries are more or less likely to focus on intervention research that has the potential to reduce smoking rates among low-SES or disadvantaged groups. This is a difficult question to answer, as there are numerous dimensions that could relate to research contributions by country including: overall population density; economic factors, e.g., gross domestic product and per capita expenditure and infrastructure that are important drivers supporting research. Tobacco smoking is a global burden with its associated research output spanning both developed and developing countries. The global predictions of smoking-related disease morbidity and mortality is for an increase in smoking-related disease in developing countries, therefore a concerted effort must be made to increase smoking cessation research output within developing countries where smoking rates are highest and burden of disease overrepresented.

This review aimed to identify the number and methodological quality of published smoking cessation research relevant to low-SES and disadvantaged population groups over two time periods (TP1: 2000-2004) and (TP2: 2008-2012) and by country (Australia/New Zealand, United Kingdom, United States/Canada and Other countries).

The hypotheses were that over TP1 and TP2:

(i) Total published research output (reviews, non-data based publications, data-based publications (descriptive, measurement and intervention research)) would have significantly increased;

(ii) The proportion of the total published output that is intervention research would have significantly increased; and

(iii) The methodological quality of the published intervention research would have significantly increased: (a) the proportion of intervention studies using Cochrane Effective Practice Organisation of Care (EPOC)-accepted evaluation designs: randomised controlled trial (RCT), controlled clinical trial (CCT), controlled before and after (CBA) study, or interrupted time series (ITS) would have significantly increased; and (b) the proportion of intervention studies using biochemical verification of self-reported smoking abstinence would have significantly increased.

This review adopted a dichotomous breakdown across two time periods (TP1 and TP2) and allowed for a three year lag time period (between 2005 to 2007) to account for the implementation of the WHO 
FCTC and to identify whether the WHO FCTC may have impacted smoking cessation research output among low-SES and disadvantaged population groups. This time period took into account that final signatories for the WHO FCTC countries occurred in 2005 and that a number of steps and a substantial timeframe is needed to allow for research output to eventuate, i.e., study conceptualisation, grant proposal and funding approvals, ethics approval, implementation, data collection, data analyses and publication of research.

\section{Method}

\subsection{Data Sources}

\section{Search Strategy, Selection of Studies and Coding}

This review followed the PRISMA statement (See Table A1) for identification, screening, eligibility and inclusion of studies [26]. As summarised in Figures 1 (TP1) and 2 (TP2), Medline, Embase, PsycINFO, The Cochrane Library and Project Cork databases were searched. The search terms are described in full in the Appendix and are accessible online from the Int. J. Environ Res Public Health website. Note: "smoking cessation" was the search term used in each of the above databases.

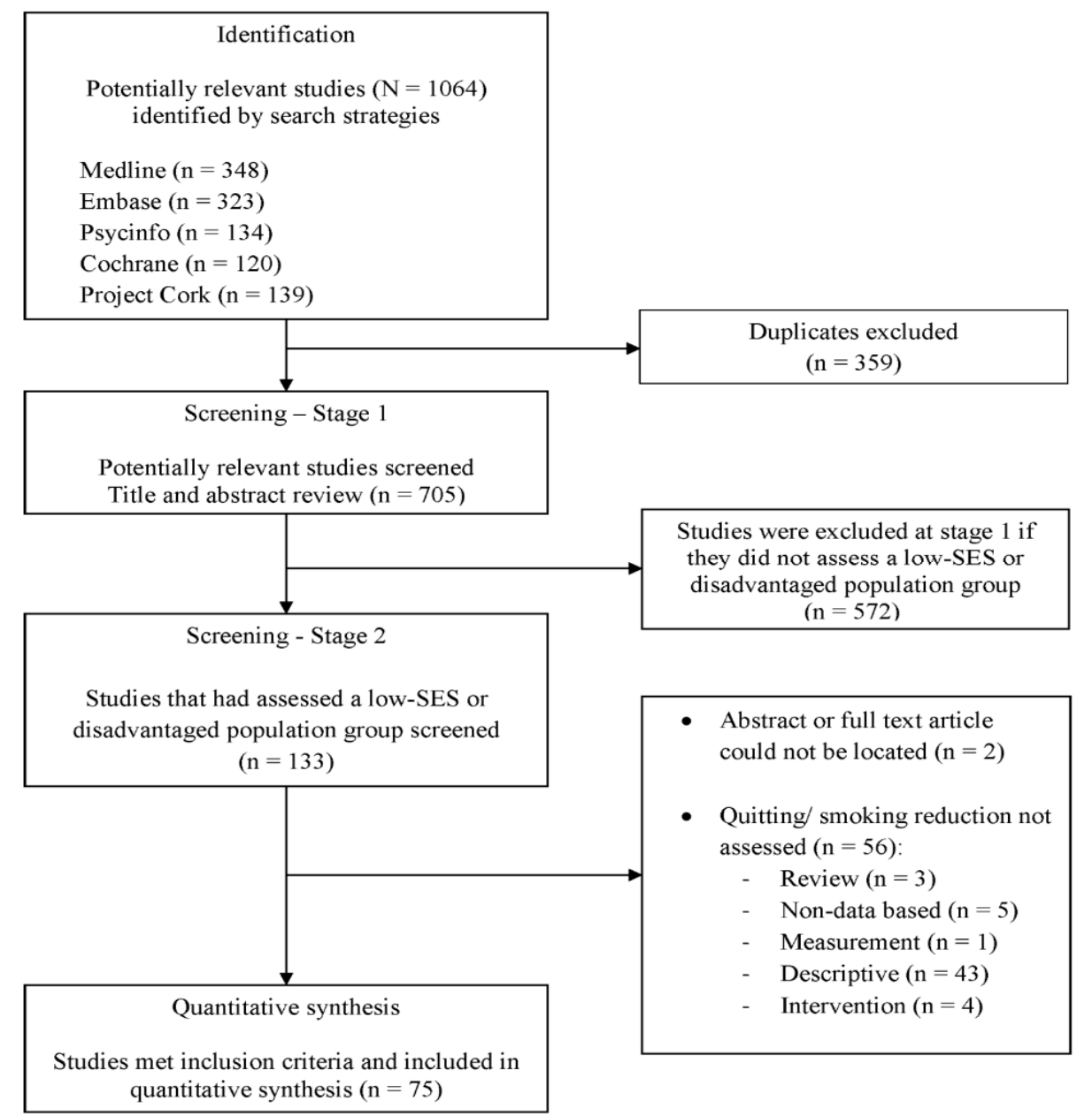

Figure 1. Flowchart of search strategy and selection criteria (2000-2004) using PRISMA guideline. 


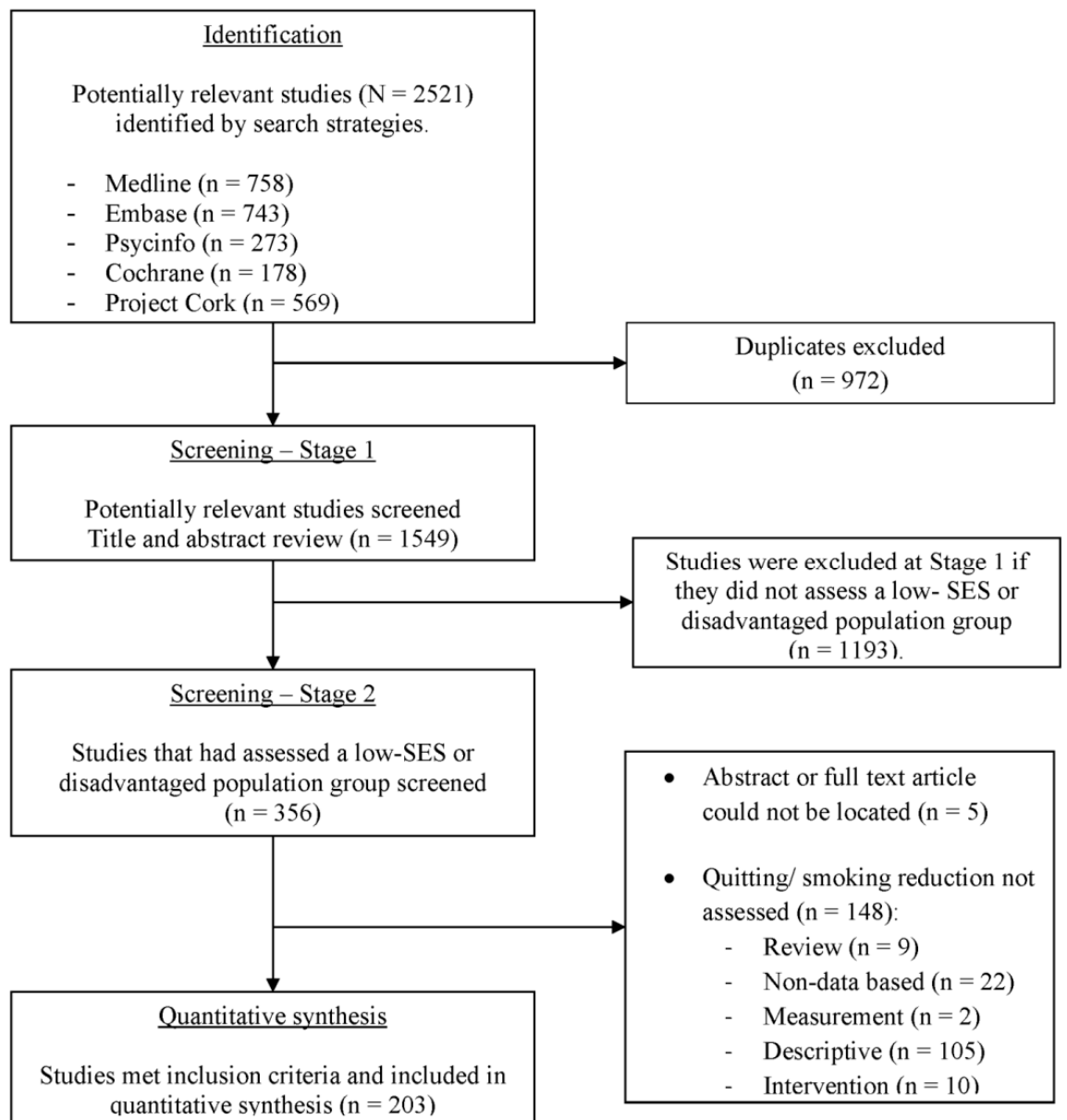

Figure 2. Flowchart of search strategy and selection criteria (2008-2012) using PRISMA guideline.

\subsection{Study Selection}

The titles and abstracts of citations were examined by author RC for relevance. Studies were included if they were: (1) written in English; (2) published within TP1: 2000-2004 or TP2: 2008-2012; and (3) examined smoking cessation among a low-SES or disadvantaged population group. Smoking cessation studies were included if they provided sustained abstinence, point-prevalence, or binary data relating to quit status (i.e., Quit (Yes/No)). Studies that had provided smoking reduction data (i.e., number of cigarettes smoked) were also included. Selected publications were coded by: country; year of publication; low-SES or type of disadvantaged population group targeted (homeless, Indigenous, prisoners, at-risk youth, schizophrenia, depression, and other mental illness). Low-SES was defined as persons who: had a low fixed household income; were Medicaid recipients; or lived in impoverished neighbourhoods or disadvantaged communities. The disadvantaged population groups were selected as they are priority population groups with high rates of smoking compared to the general population and, in addition, the burden of illness associated with tobacco use is overrepresented in such populations groups. No limitations were set on type of smoking cessation research included in the review, e.g., behavioural, pharmacological or any policy relevant tobacco control measures, i.e., taxation. 


\subsection{Data Extraction}

\subsubsection{Publication Volume and Types}

Publications were coded into three study types similar to previous reviews investigating public health research output [24,25,27]: (i) Reviews-publications specified as a "review" in the title or abstract or summarising previous research; (ii) Non data-based research-reports of study protocols, commentaries, opinion articles and case studies; and (iii) Data-based research-publications reporting new data or analysis of existing data.

Data-based research publications were further coded by study type (descriptive, measurement or intervention), defined as: (i) Descriptive-data-based epidemiologic research that examined smoking cessation or reduction using qualitative or quantitative methods that had not used an intervention; (ii) Measurement-publications exploring the development of models, psychometric analysis of an instrument or validation of a measurement tool; and (iii) Intervention research-publications that evaluated the effectiveness of smoking cessation intervention(s) aimed at smoking cessation and/or reduction interventions.

\subsubsection{Evaluation Designs and Biochemical Verification}

Intervention research was classified according to the EPOC data collection checklist for study evaluation design [28]: randomised controlled trial (RCT), controlled clinical trial (CCT), controlled before and after study (CBA) and interrupted time series (ITS). Other evaluation designs were coded as "Non-EPOC". Intervention studies were also assessed for use of biochemical verification of smoking abstinence. Author RC identified the intervention studies, which were then coded according to their evaluation design and biochemical verification status by RC and PC independently of each other. There was over 95\% agreement between coders. Differences were resolved by discussion.

\subsection{Statistical Analyses}

A Poisson regression model was fitted to the generalized estimating equation (GEE) with an autoregressive working correlation matrix specified, in order to account for the effect of clustering in the examined time categories (TP1 and TP2) when counting the number of research publication over the two dichotomous time periods [29]. This type of working correlation matrix was chosen due to the proportional relationship between the numbers of published studies within countries over two separate time categories with the number of total publications. The proportion of intervention studies were compared over the two time categories and stratified by country and by methodological quality as categorised by EPOC adherence or not; in addition to the proportion of intervention studies using biochemical verification of self-reported smoking abstinence. A Wald Chi-square statistic was used to assess the change in the proportion of intervention studies across countries and for methodological rigour between the two time categories. SPSS 22 was used to address each of these outcomes, and to model the Poisson regression within the GEE. 


\section{Results}

\subsection{Data Synthesis}

Identification of Studies

The literature search results are summarised in Figures 1 (TP1) and 2 (TP2). In TP1, 1064 articles were identified, of which 75 articles met the inclusion criteria. In TP2, 2521 articles were identified, of which 203 met the inclusion criteria (See Figures 1 and 2).

\subsection{Volume of Research}

The Poisson regression was fitted to the GEE, with time and country as predictors of research output. The results showed that there were no significant main or interaction effects of time and country on overall research output when the effects of clustering are accounted for in the analysis. However it must be noted that research output did show a trend of overall increase in the number of publications across both time periods in all countries from 75 studies in TP1 (27\% of all studies) to 203 studies in TP2 (73\% of all studies). Of those, as indicated in Table 1, 43 (57\% of total in TP1) studies in TP1 and 112 (55\% of TP2) in TP2 were data based.

Table 1. Research output by country, publication type and time period represented by number of publications and proportion (\%) output.

\begin{tabular}{ccccc}
\hline \multirow{2}{*}{ Country } & \multicolumn{2}{c}{ TP1 } & \multicolumn{2}{c}{ TP2 } \\
\cline { 2 - 5 } & Descriptive $^{\text {a }}$ & Intervention & Descriptive & Intervention \\
\hline \multirow{2}{*}{ Australia/New Zealand } & 1 & 3 & 4 & 9 \\
& $(25 \%)$ & $(75 \%)$ & $(31 \%)$ & $(69 \%)$ \\
\hline \multirow{2}{*}{ United States/Canada } & 6 & 26 & 31 & 54 \\
& $(19 \%)$ & $(81 \%)$ & $(36 \%)$ & $(64 \%)$ \\
\hline \multirow{2}{*}{ United Kingdom } & 2 & 3 & 0 & 1 \\
& $(40 \%)$ & $(60 \%)$ & $(0 \%)$ & $(100 \%)$ \\
\hline \multirow{2}{*}{ Other } & 1 & 1 & 2 & 11 \\
& $(50 \%)$ & $(50 \%)$ & $(15 \%)$ & $(85 \%)$ \\
\hline Total & 10 & 33 & 37 & 75 \\
\hline
\end{tabular}

Data-based (descriptive or intervention) research output also increased between TP1 ( $n=43$ studies) and TP2 $(n=112)$. However, the proportion of data-based research that focussed on interventions did not increase between TP1 (77\%-33/43) and TP2 (67\%-75/112). This pattern of intervention research output was consistent for Australia $\left(\chi^{2}=0.05, p=0.83\right)$, the United States and Canada $\left(\chi^{2}=3.4\right.$, $p=0.07)$, the United Kingdom $\left(\chi^{2}=0.6, p=0.44\right)$ and other countries $\left(\chi^{2}=1.3, p=0.26\right)$.

\subsection{Specific Low-SES and Disadvantaged Populations by Country}

Table 2 shows no statistically significant change in the population groups studied from TP1 to TP2 $\left(\chi^{2}=4.8, p=0.3\right)$. Note: due to small cell sizes, the mental illness category comprises schizophrenia, 
depression and other mental health disorders, and homeless was combined with low-SES. This pattern was consistent across countries.

Table 2. Research output by country and population group across time periods represented by number of publications and proportion (\%) output.

\begin{tabular}{|c|c|c|c|c|c|c|c|c|c|c|c|c|}
\hline \multirow[b]{2}{*}{ Country } & \multicolumn{6}{|c|}{ TP1 } & \multicolumn{6}{|c|}{ TP2 } \\
\hline & 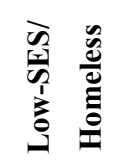 & 吾晜 & 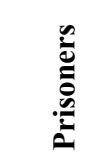 & 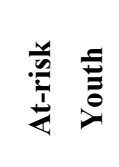 & 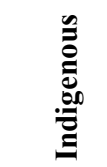 & Total & 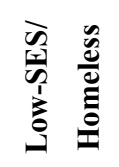 & 忢总 & 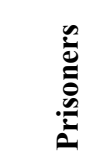 & 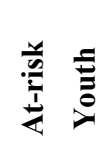 & 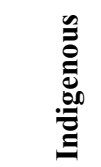 & Total \\
\hline $\begin{array}{c}\text { Australia/ } \\
\text { New Zealand }\end{array}$ & $\begin{array}{c}0 \\
(0 \%)\end{array}$ & $\begin{array}{c}5 \\
(45 \%) \\
\end{array}$ & $\begin{array}{c}2 \\
(18 \%) \\
\end{array}$ & $\begin{array}{c}0 \\
(0 \%)\end{array}$ & $\begin{array}{c}4 \\
(36 \%) \\
\end{array}$ & 11 & $\begin{array}{c}5 \\
(15 \%) \\
\end{array}$ & $\begin{array}{c}12 \\
(35 \%) \\
\end{array}$ & $\begin{array}{c}4 \\
(12 \%) \\
\end{array}$ & $\begin{array}{c}0 \\
(0 \%) \\
\end{array}$ & $\begin{array}{c}13 \\
(38 \%) \\
\end{array}$ & 34 \\
\hline $\begin{array}{c}\text { United States/ } \\
\text { Canada }\end{array}$ & $\begin{array}{c}11 \\
(21 \%) \\
\end{array}$ & $\begin{array}{c}29 \\
(56 \%) \\
\end{array}$ & $\begin{array}{c}1 \\
(2 \%) \\
\end{array}$ & $\begin{array}{c}7 \\
(13 \%) \\
\end{array}$ & $\begin{array}{c}4 \\
(8 \%) \\
\end{array}$ & 52 & $\begin{array}{c}33 \\
(24 \%) \\
\end{array}$ & $\begin{array}{c}76 \\
(55 \%) \\
\end{array}$ & $\begin{array}{c}7 \\
(5 \%) \\
\end{array}$ & $\begin{array}{c}7 \\
(5 \%) \\
\end{array}$ & $\begin{array}{c}16 \\
(12 \%) \\
\end{array}$ & 139 \\
\hline $\begin{array}{c}\text { United } \\
\text { Kingdom }\end{array}$ & $\begin{array}{c}8 \\
(89 \%)\end{array}$ & $\begin{array}{c}0 \\
(0 \%)\end{array}$ & $\begin{array}{c}1 \\
(11 \%)\end{array}$ & $\begin{array}{c}0 \\
(0 \%)\end{array}$ & $\begin{array}{c}0 \\
(0 \%)\end{array}$ & 9 & $\begin{array}{c}2 \\
(29 \%)\end{array}$ & $\begin{array}{c}4 \\
(57 \%)\end{array}$ & $\begin{array}{c}1 \\
(14 \%)\end{array}$ & $\begin{array}{c}0 \\
(0 \%)\end{array}$ & $\begin{array}{c}0 \\
(0 \%)\end{array}$ & 7 \\
\hline Other & $\begin{array}{c}0 \\
(0 \%)\end{array}$ & $\begin{array}{c}3 \\
(100 \%)\end{array}$ & $\begin{array}{c}0 \\
(0 \%)\end{array}$ & $\begin{array}{c}0 \\
(0 \%)\end{array}$ & $\begin{array}{c}0 \\
(0 \%)\end{array}$ & 3 & $\begin{array}{c}5 \\
(22 \%)\end{array}$ & $\begin{array}{c}18 \\
(78 \%)\end{array}$ & $\begin{array}{c}0 \\
(0 \%)\end{array}$ & $\begin{array}{c}0 \\
(0 \%)\end{array}$ & $\begin{array}{c}0 \\
(0 \%)\end{array}$ & 23 \\
\hline Total & $\begin{array}{c}19 \\
(25 \%)\end{array}$ & $\begin{array}{c}37 \\
(49 \%)\end{array}$ & $\begin{array}{c}4 \\
(5 \%)\end{array}$ & $\begin{array}{c}7 \\
(9 \%)\end{array}$ & $\begin{array}{c}8 \\
(11 \%)\end{array}$ & 75 & $\begin{array}{c}45 \\
(22 \%)\end{array}$ & $\begin{array}{c}110 \\
(54 \%)\end{array}$ & $\begin{array}{c}12 \\
(6 \%)\end{array}$ & $\begin{array}{c}7 \\
(3 \%)\end{array}$ & $\begin{array}{c}29 \\
(14 \%)\end{array}$ & 203 \\
\hline
\end{tabular}

\subsection{Proportion of Intervention Studies}

Table 3 shows that the number of both EPOC and non-EPOC evaluation designs increased over time: 21 (TP1) to 44 (TP2); and 12 (TP1) to 31 (TP2), respectively. Within the EPOC studies, the proportion that were RCTs remained comparable from T1 $(64 \%)$ to T2 $(57 \%)\left(\chi^{2}=0.24, p=0.63\right)$.

Table 3. Number of intervention studies and respective EPOC evaluation design used by country represented by number of publications and proportion (\%) output.

\begin{tabular}{|c|c|c|c|c|c|c|c|c|}
\hline \multirow{3}{*}{ Country } & \multicolumn{4}{|c|}{ TP1 } & \multicolumn{4}{|c|}{ TP2 } \\
\hline & \multicolumn{2}{|c|}{ EPOC } & \multirow{2}{*}{ Non-EPOC } & \multirow{2}{*}{ Total } & \multicolumn{2}{|c|}{ EPOC } & \multirow{2}{*}{ Non-EPOC } & \multirow{2}{*}{ Total } \\
\hline & RCT & CCT & & & RCT & CCT & & \\
\hline Australia/New Zealand & $\begin{array}{c}1 \\
(33 \%)\end{array}$ & $\begin{array}{c}0 \\
(0 \%)\end{array}$ & $\begin{array}{c}2 \\
(67 \%)\end{array}$ & 3 & $\begin{array}{c}2 \\
(22 \%)\end{array}$ & $\begin{array}{c}0 \\
(0 \%)\end{array}$ & $\begin{array}{c}7 \\
(78 \%) \\
\end{array}$ & 9 \\
\hline United States/Canada & $\begin{array}{c}17 \\
(65 \%)\end{array}$ & $\begin{array}{c}0 \\
(0 \%)\end{array}$ & $\begin{array}{c}9 \\
(35 \%)\end{array}$ & 26 & $\begin{array}{c}34 \\
(63 \%) \\
\end{array}$ & $\begin{array}{c}1 \\
(2 \%)\end{array}$ & $\begin{array}{c}19 \\
(35 \%)\end{array}$ & 54 \\
\hline United Kingdom & $\begin{array}{c}2 \\
(67 \%)\end{array}$ & $\begin{array}{c}0 \\
(0 \%)\end{array}$ & $\begin{array}{c}1 \\
(33 \%)\end{array}$ & 3 & $\begin{array}{c}0 \\
(0 \%)\end{array}$ & $\begin{array}{c}0 \\
(0 \%)\end{array}$ & $\begin{array}{c}1 \\
(100 \%)\end{array}$ & 1 \\
\hline Other & $\begin{array}{c}1 \\
(100 \%)\end{array}$ & $\begin{array}{c}0 \\
(0 \%)\end{array}$ & $\begin{array}{c}0 \\
(0 \%) \\
\end{array}$ & 1 & $\begin{array}{c}7 \\
(64 \%) \\
\end{array}$ & $\begin{array}{c}0 \\
(0 \%) \\
\end{array}$ & $\begin{array}{c}4 \\
(36 \%) \\
\end{array}$ & 11 \\
\hline Total & $\begin{array}{c}21 \\
(64 \%)\end{array}$ & $\begin{array}{c}0 \\
(0 \%)\end{array}$ & $\begin{array}{c}12 \\
(36 \%)\end{array}$ & 33 & $\begin{array}{c}43 \\
(57 \%)\end{array}$ & $\begin{array}{c}1 \\
(1 \%)\end{array}$ & $\begin{array}{c}31 \\
(41 \%)\end{array}$ & 75 \\
\hline
\end{tabular}

There were no EPOC endorsed designs other than RCTs and CCTs. 


\subsection{Methodological Quality of Intervention Studies}

\subsubsection{Evaluation Designs}

Although the number of intervention studies using EPOC-accepted evaluation design across population groups had increased from 21 in TP1 to 44 in TP2, the proportion of intervention studies examining each population group (see Table 4) remained consistent from TP1 to TP2 $\left(\chi^{2}=3.97, p=0.41\right)$.

Table 4. Number of intervention studies using EPOC accepted evaluation design by country and population group represented by number of publications and proportion (\%) output.

\begin{tabular}{|c|c|c|c|c|c|c|c|c|c|c|c|c|}
\hline \multirow[b]{2}{*}{ Country } & \multicolumn{6}{|c|}{ TP1 } & \multicolumn{6}{|c|}{ TP2 } \\
\hline & 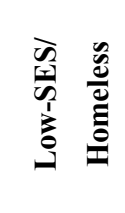 & 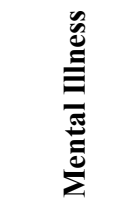 & 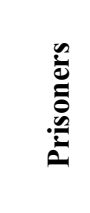 & 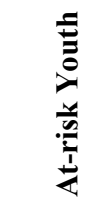 & 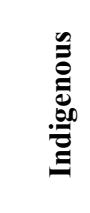 & Total & 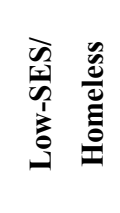 & 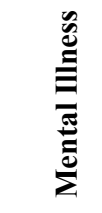 & 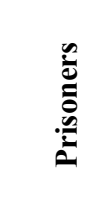 & 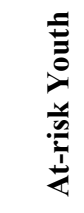 & 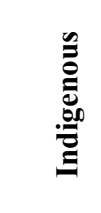 & Total \\
\hline $\begin{array}{c}\text { Australia/ } \\
\text { New } \\
\text { Zealand }\end{array}$ & $\begin{array}{c}0 \\
(0 \%)\end{array}$ & $\begin{array}{c}1 \\
(100 \%)\end{array}$ & $\begin{array}{c}0 \\
(0 \%)\end{array}$ & $\begin{array}{c}0 \\
(0 \%)\end{array}$ & $\begin{array}{c}0 \\
(0 \%)\end{array}$ & 1 & $\begin{array}{c}0 \\
(0 \%)\end{array}$ & $\begin{array}{c}1 \\
(50 \%)\end{array}$ & $\begin{array}{c}0 \\
(0 \%)\end{array}$ & $\begin{array}{c}0 \\
(0 \%)\end{array}$ & $\begin{array}{c}1 \\
(50 \%)\end{array}$ & 2 \\
\hline $\begin{array}{l}\text { United } \\
\text { States/ } \\
\text { Canada }\end{array}$ & $\begin{array}{c}4 \\
(24 \%)\end{array}$ & $\begin{array}{c}9 \\
(53 \%)\end{array}$ & $\begin{array}{c}0 \\
(0 \%)\end{array}$ & $\begin{array}{c}3 \\
(18 \%)\end{array}$ & $\begin{array}{c}1 \\
(6 \%)\end{array}$ & 17 & $\begin{array}{c}9 \\
(26 \%)\end{array}$ & $\begin{array}{c}19 \\
(54 \%)\end{array}$ & $\begin{array}{c}4 \\
(11 \%)\end{array}$ & $\begin{array}{c}2 \\
(6 \%)\end{array}$ & $\begin{array}{c}1 \\
(3 \%)\end{array}$ & 35 \\
\hline $\begin{array}{c}\text { United } \\
\text { Kingdom }\end{array}$ & $\begin{array}{c}2 \\
(100 \%)\end{array}$ & $\begin{array}{c}0 \\
(0 \%) \\
\end{array}$ & $\begin{array}{c}0 \\
(0 \%)\end{array}$ & $\begin{array}{c}0 \\
(0 \%) \\
\end{array}$ & $\begin{array}{c}0 \\
(0 \%)\end{array}$ & 2 & $\begin{array}{c}0 \\
(0 \%)\end{array}$ & $\begin{array}{c}0 \\
(0 \%)\end{array}$ & $\begin{array}{c}0 \\
(0 \%)\end{array}$ & $\begin{array}{c}0 \\
(0 \%) \\
\end{array}$ & $\begin{array}{c}0 \\
(0 \%)\end{array}$ & 0 \\
\hline Other & $\begin{array}{c}0 \\
(0 \%) \\
\end{array}$ & $\begin{array}{c}1 \\
(100 \%) \\
\end{array}$ & $\begin{array}{c}0 \\
(0 \%) \\
\end{array}$ & $\begin{array}{c}0 \\
(0 \%) \\
\end{array}$ & $\begin{array}{c}0 \\
(0 \%) \\
\end{array}$ & 1 & $\begin{array}{c}1 \\
(14 \%) \\
\end{array}$ & $\begin{array}{c}6 \\
(86 \%) \\
\end{array}$ & $\begin{array}{c}0 \\
(0 \%) \\
\end{array}$ & $\begin{array}{c}0 \\
(0 \%) \\
\end{array}$ & $\begin{array}{c}0 \\
(0 \%) \\
\end{array}$ & 7 \\
\hline Total & $\begin{array}{c}6 \\
(29 \%)\end{array}$ & $\begin{array}{c}11 \\
(52 \%)\end{array}$ & $\begin{array}{c}0 \\
(0 \%)\end{array}$ & $\begin{array}{c}3 \\
(14 \%)\end{array}$ & $\begin{array}{c}1 \\
(5 \%)\end{array}$ & 21 & $\begin{array}{c}10 \\
(23 \%)\end{array}$ & $\begin{array}{c}26 \\
(59 \%)\end{array}$ & $\begin{array}{c}4 \\
(9 \%)\end{array}$ & $\begin{array}{c}2 \\
(5 \%)\end{array}$ & $\begin{array}{c}2 \\
(5 \%)\end{array}$ & 44 \\
\hline
\end{tabular}

\subsubsection{Use of Biochemical Verification}

Of the intervention studies (33 in TP1 and 75 in TP2) the proportion that used biochemical verification of smoking status declined significantly from TP1 $88 \%$ to $64 \%$ at TP2 $\left(\chi^{2}=6.39, p=0.01\right)$. There was a significant difference in the use of biochemical verification by EPOC design type: of the 65 RCTs or CCTs, $82 \%$ ( $n=53$ studies) used some form of biochemical verification, compared to $56 \%$ ( $n=24$ studies) of the 43 "Non-EPOC" evaluation designs $\left(\chi^{2}=8.37, p<0.01\right)$.

\section{Discussion}

\subsection{Summary of Findings}

While the total number of published studies increased from TP1 to TP2 (confirmation of hypothesis 1), the proportion of intervention research did not significantly change over time (contrary to hypothesis 2), nor did the proportion of intervention research that had used an EPOC-accepted evaluation design or any increase in biochemical verification of self-reported smoking status (contrary to hypothesis 3 ). 


\subsection{Increasing Output of Methodologically Rigorous Intervention Research}

Using Accepted EPOC Evaluation Designs

Although it is acknowledged that RCTs are not always feasible, EPOC has identified a number of alternatives that provide sufficiently rigorous evidence [30,31]. Such alternative research designs (e.g., multiple baseline design) have an added benefit of being more cost- and time-efficient than RCTs and their integration into policy may be more feasible [30,32]. The apparent lack of proportional increase in implementing these alternatives, or RCTs, in smoking cessation interventions for low-SES and disadvantaged population groups should be addressed as a priority in future smoking cessation studies.

Several potential options are available to increase the output of methodologically robust intervention studies. First, incentivising and providing strategic funding towards EPOC-accepted evaluation designs may assist in increasing such outputs [24,25]. There may be significant value in research granting bodies prioritising the allocation of funding towards intervention studies using methodologically sound designs. At an institutional level, performance indicators of researchers could be shifted towards a focus on methodological quality of researchers' outputs and their potential to impact on health care policy [24,25]. If research institutions incentivised and rewarded publications accepted in Cochrane Database of Systematic Reviews, there may be an increased impetus for academics to develop methodologically rigorous interventions [24,25]. In addition, journal publishers could reorient their publication criteria to have a greater focus on methodological adequacy of studies rather than significance of results [24,25]. There have been calls for the establishment of research centres and collaborations designed to meet the distinct needs of distinct population groups in a co-ordinated manner [33-35]. Such a strategic and focused research effort may present a number of positive flow on effects including: pooling of funding and resources; knowledge gathering and translation; access to multidisciplinary advice; promotion of a high-quality research agenda; and expanding and developing partnerships with community organisations and stakeholders to increase recruitment and retention [33].

It is also important consumer advisory groups (CAGs) are involved in priority-driven research agendas and the direction of future intervention research among low-SES and disadvantaged population groups. CAGs can provide valuable information on effective and time efficient strategies for recruitment, retention, and intervention delivery [36]. At a provider-level, it is also recognised that staff at health and community organisations may not have the confidence or empowerment to implement intervention research [37]. A concerted effort needs to be made to encourage CAGs, health care organisations, staff and health practitioners to partner, engage and help to foster and increase intervention research output.

\subsection{Increasing the Use of Biochemical Verification of Self-Reported Abstinence}

In addition to increasing the use of rigorous evaluation designs, this review highlights that improvements in the reporting of biochemical verification of self-reported smoking may be warranted. The use of biochemical verification is central to determining the accuracy of smoking abstinence claims and is used in nearly all publications in high-impact journals [38]. It is largely acknowledged that among special populations or for clinic-based interventions biochemical verification does add 
higher precision [39,40]. Self-reported smoking prevalence using standard methods has been shown to underestimate national smoking prevalence estimates across countries with cotinine concentrations in misclassified non-smokers typically indicative of high levels of smoking and/or exposure to smoke [41]. There is a need for correction of self-reported estimates using biochemical markers, as success or failure of tobacco control measures and smoking cessation intervention research is typically measured by changes in smoking rates of a few percentage points and consideration of even low error rates are extremely important [41]. The fact that only $70 \%$ of intervention studies identified in this review used biochemical verification, and its significant decline in use from TP1 to TP2, suggests it could be used more frequently. Allowing for biochemical verification to verify health behaviours such as smoking cessation is of particular importance in countering the Hawthorne effect that may lead to misclassification due to the reluctance of participants to report that they have failed to cease smoking [38,42]. A double blind controlled study may still not counter all three components of this phenomenon since controlling for "treatment", "observation" and "experimenter" bias may not be feasible, practical or even desired since these effects may in fact improve the saliency of the intervention [43]. Biochemical verification would provide insights into this often neglected but important phenomenon. However, careful consideration must be made about the feasibility of biochemical verification outside of clinically-oriented behavioral or pharmacological interventions as for some interventions, e.g., taxation, media and other policy interventions biochemical verification may not be feasible.

\subsection{Study Limitations}

Despite using an extensive search strategy across several databases, including citations from developing and developed countries, it is possible that some eligible studies were excluded. Hand searching, in addition to electronic searching, is recommended as an additional search strategy [44] but the large number of citations identified across both time periods ( $n=278$ citations) meant that this task was neither practical nor feasible. A combination of explode and focus commands on subject headings were used to achieve a high level of sensitivity and specificity for the literature search. The * symbol was used before the search statement "smoking cessation" to ensure we identified results where this term was a major topic or focus. Further, it is acknowledged that the use of additional terms, e.g., "tobacco use cessation" and not limiting the search to "humans" and "English language" may have provided a more sensitive search string. This may have meant that some studies where smoking cessation was not a primary focus were missed but the likelihood of any such bias would have been equal across country and low-SES and disadvantaged population groups studied. This review used number of published articles as a proxy for research output, however, citation analysis is an alternative measure that could be used to assess research quality in the future. EPOC evaluation design categories were used as the measure of methodological quality of studies, rather than applying additional criteria. Nonetheless, the relatively high proportion (40\%) that did not meet basic EPOC evaluation design criteria is concerning because it is difficult to be confident of a causal relationship between the intervention and the outcome, irrespective of the quality of other design features. This problem has also been identified in other reviews examining research output in indigenous health, low-SES groups, quality of life and other public health research $[24,25,27,45,46]$. 


\section{Conclusions}

The purpose of this review was to identify the pattern of research output among low-SES and disadvantaged population groups and to encourage debate on how research efforts should be directed to improve knowledge and increase output of methodologically sound smoking cessation research. The current review findings coupled with a paucity of methodological rigorous intervention research aimed at low-SES and disadvantaged populations groups indicates that tobacco-related health inequalities, high rates of smoking, and high economic costs may continue in the foreseeable future. The development and implementation of high quality intervention research among low-SES and disadvantaged population groups remains a high clinical and economic priority. Both funding bodies and researchers alike must critically reflect on the suboptimal output of intervention research. Identifying mechanisms to effect change may be difficult, but it is of utmost importance to allocate research resources that contribute most effectively to health gain through the application of evidence-based practice [25].

\section{Acknowledgments}

We thank Mary Kumvaj (Librarian, NDARC, UNSW) for her assistance and advice on search strategies used in this review. This research is funded by a grant from the National Health and Medical Research Council (NHMRC) of Australia (GNT1021862), and RPM is supported by a NHMRC Principal Research Fellowship (GNT1045318). Lead author RJC is supported by a Cancer Institute NSW Early Career Fellowship. The National Drug and Alcohol Research Centre at the UNSW Australia is supported by funding from the Australian Government under the Substance Misuse Prevention and Service Improvements Grants Fund.

\section{Author Contributions}

All authors contributed to the conceptualisation of the systematic review. Ryan James Courtney conducted the literature searches and scanning of articles with assistance from Philip Clare. Ryan James Courtney devised the initial draft. EPOC coding was conducted by Ryan James Courtney with cross checking completed by Philip Clare. Sundresan Naicker undertook the statistical analyses with feedback provided from Philip Clare and Ryan James Courtney. All authors (Ryan James Courtney, Sundresan Naicker, Anthony Shakeshaft, Philip Clare, Kristy Martire and Richard Mattick) provided feedback and contributions to the review and adhered to ICMJE criteria for authorship.

\section{Appendix}

\section{Search Terms for Identification and Selection of Studies}

For MEDLINE we separately searched from 2000 to 2004 and 2008 to 2012 limited to "English language" and "Humans" using the following Medical Subject Heading (MeSH) terms and keywords: (exp * Smoking Cessation/) and (exp Socioeconomic Factors/or exp Poverty/or exp Vulnerable Populations/or exp Homeless Persons/or exp Mentally Ill Persons/or exp Mental Health/or exp Schizophrenia/or exp Anxiety/or exp Depression/or exp Prisons/or exp Prisoners/or exp Adolescent 
Behavior/or exp Juvenile Delinquency/or exp Oceanic Ancestry Group/or exp Indians, Central American/or exp Indians, North American/or exp Inuits/or “first nation\$”.mp. or “aborigin\$”.mp or "maori".mp).

For EMBASE we separately searched from 2000 to 2004 and 2008 to 2012 limited to "English language" and "Humans" using the following Emtree terms and keywords: (exp * smoking cessation/) and (exp socioeconomics/or exp social class/or exp social status/or exp poverty/or exp lowest income group/or exp vulnerable population/or exp homelessness/or exp mental patient/or exp mental health/or exp schizophrenia/or exp anxiety/or exp depression/or exp prison/or exp prisoner/or exp adolescence/or exp juvenile/or exp Aborigine/or exp American Indian/or exp indigenous people/or exp Eskimo/or exp Maori/or first nation\$.mp. or aborigin\$.mp).

For PsycINFO we separately searched from 2000 to 2004 and 2008 to 2012 limited to "English language" and "Humans" using the following PsycINFO terms and keywords: (exp * smoking cessation/) and (exp Socioeconomic Status/or exp Family Socioeconomic Level/or exp Social Class/or exp Lower Income Level/or exp Poverty/or exp Poverty Areas/or exp At Risk Populations/or exp Homeless/or exp Homeless Mentally Ill/or exp Mental Health/or exp Psychiatric Patients/or exp Schizophrenia/or exp Anxiety/or exp Major Depression/or exp Prisons/or exp Prisoners/or exp Juvenile Delinquency/or exp Indigenous Populations/or exp American Indians/or exp Inuit/or exp Alaska natives/or first nation\$.mp. or aborigin\$.mp. or maori.mp).

For The Cochrane Library we separately searched from 2000 to 2004 and 2008 to 2012 limited to "English language" and "Humans" using the following Medical Subject Heading (MeSH) terms and keywords: (smoking cessation) and (Socioeconomic factors or Vulnerable populations or Homeless persons or Mentally ill persons or Mental health or Schizophrenia or Anxiety or Depression or Prisons or Prisoners or Adolescent behaviour or Juvenile delinquency or Oceanic ancestry group or American Native Continental Ancestry Group or Aborigin * or Indigenous or Maori).

For Project Cork we separately searched from 2000 to 2004 and 2008 to 2012 limited to "English language" and "Humans" using the following Project Cork terms and keywords: (smoking cessation) and (sociological aspect or homeless or chronic mental illness or anxiety or anxiety disorder or mood disorder or depression or schizophrenia or prisoners or criminal justice system or adolescents or native peoples or Native Americans or Alaska Natives). 
Table A1. PRISMA 2009 checklist.

\begin{tabular}{|c|c|c|c|}
\hline Section/Topic & $\#$ & Checklist Item & Reported on Page \# \\
\hline \multicolumn{4}{|c|}{ TITLE } \\
\hline Title & 1 & Identify the report as a systematic review, meta-analysis, or both. & 1 \\
\hline \multicolumn{4}{|c|}{ ABSTRACT } \\
\hline Structured summary & 2 & $\begin{array}{l}\text { Provide a structured summary including, as applicable: background; objectives; data sources; study } \\
\text { eligibility criteria, participants, and interventions; study appraisal and synthesis methods; results; } \\
\text { limitations; conclusions and implications of key findings; systematic review registration number. }\end{array}$ & $1-2$ \\
\hline \multicolumn{4}{|c|}{ INTRODUCTION } \\
\hline Rationale & 3 & Describe the rationale for the review in the context of what is already known. & $2-4-5$ \\
\hline Objectives & 4 & $\begin{array}{l}\text { Provide an explicit statement of questions being addressed with reference to participants, interventions, } \\
\text { comparisons, outcomes, and study design (PICOS). }\end{array}$ & $3-4$ \\
\hline \multicolumn{4}{|c|}{ METHODS } \\
\hline $\begin{array}{l}\text { Protocol and } \\
\text { registration }\end{array}$ & 5 & $\begin{array}{l}\text { Indicate if a review protocol exists, if and where it can be accessed (e.g., Web address), and, if } \\
\text { available, provide registration information including registration number. }\end{array}$ & N/A \\
\hline Eligibility criteria & 6 & $\begin{array}{l}\text { Specify study characteristics (e.g., PICOS, length of follow-up) and report characteristics (e.g., years } \\
\text { considered, language, publication status) used as criteria for eligibility, giving rationale. }\end{array}$ & 6 \\
\hline Information sources & 7 & $\begin{array}{l}\text { Describe all information sources (e.g., databases with dates of coverage, contact with study authors to } \\
\text { identify additional studies) in the search and date last searched. }\end{array}$ & 6 \\
\hline Search & 8 & $\begin{array}{l}\text { Present full electronic search strategy for at least one database, including any limits used, such that it } \\
\text { could be repeated. }\end{array}$ & Online appendix \\
\hline Study selection & 9 & $\begin{array}{l}\text { State the process for selecting studies (i.e., screening, eligibility, included in systematic review, and, if } \\
\text { applicable, included in the meta-analysis). }\end{array}$ & $6+$ Figures \\
\hline Data collection process & 10 & $\begin{array}{l}\text { Describe method of data extraction from reports (e.g., piloted forms, independently, in duplicate) and } \\
\text { any processes for obtaining and confirming data from investigators. }\end{array}$ & N/A \\
\hline Data items & 11 & $\begin{array}{l}\text { List and define all variables for which data were sought (e.g., PICOS, funding sources) and any } \\
\text { assumptions and simplifications made. }\end{array}$ & $6-7$ \\
\hline
\end{tabular}


Table A1. Cont.

\begin{tabular}{|c|c|c|c|}
\hline Section/Topic & \# & Checklist Item & Reported on Page \# \\
\hline $\begin{array}{l}\text { Risk of bias in } \\
\text { individual studies }\end{array}$ & 12 & $\begin{array}{l}\text { Describe methods used for assessing risk of bias of individual studies (including specification of whether } \\
\text { this was done at the study or outcome level), and how this information is to be used in any data } \\
\text { synthesis. }\end{array}$ & 7. EPOC checklist \\
\hline Summary measures & 13 & State the principal summary measures (e.g., risk ratio, difference in means). & 7 \\
\hline Synthesis of results & 14 & $\begin{array}{l}\text { Describe the methods of handling data and combining results of studies, if done, including measures of } \\
\text { consistency (e.g., } \mathrm{I}^{2} \text { ) for each meta-analysis. }\end{array}$ & 7 \\
\hline $\begin{array}{l}\text { Risk of bias across } \\
\text { studies }\end{array}$ & 15 & $\begin{array}{l}\text { Specify any assessment of risk of bias that may affect the cumulative evidence (e.g., publication bias, } \\
\text { selective reporting within studies). }\end{array}$ & 12 \\
\hline Additional analyses & 16 & $\begin{array}{l}\text { Describe methods of additional analyses (e.g., sensitivity or subgroup analyses, meta-regression), if } \\
\text { done, indicating which were pre-specified. }\end{array}$ & N/A \\
\hline \multicolumn{4}{|c|}{ RESULTS } \\
\hline Study selection & 17 & $\begin{array}{l}\text { Give numbers of studies screened, assessed for eligibility, and included in the review, with reasons for } \\
\text { exclusions at each stage, ideally with a flow diagram. }\end{array}$ & $8+$ Figures \\
\hline Study characteristics & 18 & $\begin{array}{l}\text { For each study, present characteristics for which data were extracted (e.g., study size, PICOS, follow-up } \\
\text { period) and provide the citations. }\end{array}$ & 7 \\
\hline $\begin{array}{l}\text { Risk of bias within } \\
\text { studies }\end{array}$ & 19 & Present data on risk of bias of each study and, if available, any outcome level assessment (see item 12). & 7. EPOC checklist \\
\hline $\begin{array}{l}\text { Results of individual } \\
\text { studies }\end{array}$ & 20 & $\begin{array}{l}\text { For all outcomes considered (benefits or harms), present, for each study: (a) simple summary data for } \\
\text { each intervention group (b) effect estimates and confidence intervals, ideally with a forest plot. }\end{array}$ & $\mathrm{N} / \mathrm{A}$ \\
\hline Synthesis of results & 21 & Present results of each meta-analysis done, including confidence intervals and measures of consistency. & N/A \\
\hline $\begin{array}{l}\text { Risk of bias across } \\
\text { studies }\end{array}$ & 22 & Present results of any assessment of risk of bias across studies (see Item 15). & N/A \\
\hline Additional analysis & 23 & $\begin{array}{l}\text { Give results of additional analyses, if done (e.g., sensitivity or subgroup analyses, meta-regression } \\
\text { (see Item 16)). }\end{array}$ & N/A \\
\hline
\end{tabular}


Table A1. Cont.

\begin{tabular}{|c|c|c|c|}
\hline Section/Topic & $\#$ & Checklist Item & Reported on Page \# \\
\hline \multicolumn{4}{|c|}{ DISCUSSION } \\
\hline Summary of evidence & 24 & $\begin{array}{l}\text { Summarize the main findings including the strength of evidence for each main outcome; consider their } \\
\text { relevance to key groups (e.g., healthcare providers, users, and policy makers). }\end{array}$ & $10-13$ \\
\hline Limitations & 25 & $\begin{array}{l}\text { Discuss limitations at study and outcome level (e.g., risk of bias), and at review-level (e.g., incomplete } \\
\text { retrieval of identified research, reporting bias). }\end{array}$ & 12 \\
\hline Conclusions & 26 & $\begin{array}{l}\text { Provide a general interpretation of the results in the context of other evidence, and implications for future } \\
\text { research. }\end{array}$ & 13 \\
\hline \multicolumn{4}{|c|}{ FUNDING } \\
\hline Funding & 27 & $\begin{array}{l}\text { Describe sources of funding for the systematic review and other support (e.g., supply of data); role of } \\
\text { funders for the systematic review. }\end{array}$ & 13 \\
\hline
\end{tabular}

Statement. PLoS Med. 2009, 6, e1000097, doi:10.1371/journal.pmed1000097; For more information, visit: www.prisma-statement.org. 


\section{Conflicts of Interest}

The authors declare no conflict of interest.

\section{References}

1. Chaloupka, F.J.; The World Bank. Curbing the epidemic: Governments and the economics of tobacco control. Tob. Control 1999, 8, 196-201.

2. Ezzati, M.; Lopez, A.D. Estimates of global mortality attributable to smoking in 2000. Lancet 2003, 362, 847-852.

3. Australian Institute of Health and Welfare. 2010 National Drug Strategy Household Survey Report. Available online: http://www.aihw.gov.au/publication-detail/?id=32212254712 (accessed on 15 January 2014).

4. Centers for Disease Control \& Prevention. Cigarette smoking among adults and trends in smoking cessation-United States, 2008. Morb. Mort. Wkly. Rep. 2009, 58, 1227-1258.

5. Reid, J.L.; Hammond, D.; Boudreau, C.; Fong, G.T.; Siahpush, M. Socioeconomic disparities in quit intentions, quit attempts, and smoking abstinence among smokers in four western countries: Findings from the International Tobacco Control Four Country Survey. Nicotine Tob. Res. 2010, $12, \mathrm{~S} 20-\mathrm{S} 33$.

6. Siahpush, M.; McNeill, A.; Borland, R.; Fong, G.T. Socioeconomic variations in nicotine dependence, self-efficacy, and intention to quit across four countries: Findings from the International Tobacco Control (ITC) Four Country Survey. Tob. Control 2006, 15, iii71-iii75.

7. Global Tobacco Surveillance System. Available online: http://www.who.int/tobacco/ surveillance/en/ (accessed on 15 February 2014).

8. STEPwise Approach to Surveillance. Available online: http:/www.who.int/chp/steps/en/ (accessed on 17 February 2014).

9. World Health Survey. Available online: http://www.who.int/healthinfo/survey/en/ (accessed on 12 February 2014).

10. Hozzeinpoor, A.R.; Parker, L.A.; d'Espaignet, E.T.; Chatterji, S. Social determinants of smoking in low- and middle-income countries: Results from the World Health Survey. PLoS ONE 2011, 6, doi:10.1371/journal.pone.0020331.

11. Le Cook, B.; Wayne, G.F.; Kafali, N.; Liu, Z.; Shu, C.; Flores, M. Trends in smoking among adults with mental illness and association between mental health treatment and smoking cessation. JAMA 2014, 311, 177-182.

12. Baggett, T.P.; Rigotti, N.A. Cigarette smoking and advice to quit in a national sample of homeless adults. Am. J. Prev. Med. 2010, 39, 164-172.

13. Connor, S.E.; Cook, R.L.; Herbert, M.I.; Neal, S.M.; Williams, J.T. Smoking cessation in a homeless population: There is a will, but is there a way? J. Gen. Intern. Med. 2002, 17, 369-372.

14. Robertson, J.; Conigrave, K.; Ivers, R.; Hindmarsh, E.; Clough, A. Addressing high rates of smoking in remote Aboriginal communities: New evidence for GPs. Aust. Fam. Phys. 2013, 42, 492-496. 
15. Thomas, D.P. Changes in smoking intensity among Aboriginal and Torres Strait Islander people. 1994-2008. Med. J. Aust. 2012, 197, 503-506.

16. Binswanger, I.A.; Carson, A.E.; Krueger, P.M.; Mueller, S.R.; Steiner, J.F.; Sabol, W.J. Prison tobacco control policies and deaths from smoking in United States prisons: Population based retrospective analysis. BMJ 2014, 349, doi:10.1136/bmj.g4542.

17. Sharma, A.; Lewis, S.; Szatkowski, L. Insights into social disparities in smoking prevalence using Mosaic, a novel measure of socioeconomic status: An analysis using a large primary care dataset. BMC Public Health 2010, 10, doi:10.1186/1471-2458-10-755.

18. Jha, P.; Peto, R.; Zatonski, W.; Boreham, J.; Jarvis, M.J.; Lopez, A.D. Social inequalities in male mortality, and in male mortality from smoking: Indirect estimation from national death rates in England and Wales, Poland, and North America. Lancet 2006, 368, 367-370.

19. Wanless, D. Securing Good Health for the Whole Population. Final Report. Available online: http://webarchive.nationalarchives.gov.uk/+/http:/www.hm-treasury.gov.uk/media/D/3/ Wanless04_summary.pdf (accessed on 16 January 2014).

20. Wu, Q.; Szatkowski, L.; Britton, J.; Parrott, S. Economic cost of smoking in people with mental disorders in the UK. Tob. Control 2014, 7, doi:10.1136/tobaccocontrol-2013-051464.

21. WHO Framework Convention on Tobacco Control. Available online: http://whqlibdoc.who.int/ publications/2003/9241591013.pdf?ua=1 (accessed on 8 January 2014).

22. World Health Organisation Framework Convention on Tobacco Control: Guidelines for implementation. Available online: http://apps.who.int/iris/bitstream/10665/80510/1/9789241505185_ eng.pdf?ua=1 (accessed on 19 January 2014).

23. Courtney, R.J.; Bradford, D.; Martire, K.A.; Bonevski, B.; Borland, R.; Doran, C.; Hall, W.; Farrell, M.; Siahpush, M.; Sanson-Fisher, R.; et al. A randomized clinical trial of a financial education intervention with nicotine replacement therapy (NRT) for low socio-economic status Australian smokers: A study protocol. Addiction 2014, 109, 1602-1611.

24. Bailey, L.J.; Sanson-Fisher, R.; Aranda, S.; D’Este, C.; Sharkey, K.; Schofield, P. Quality of life research: Types of publication output over time for cancer patients, a systematic review. Eur. J. Cancer Care 2010, 19, 581-588.

25. Sanson-Fisher, R.W.; Campbell, E.M.; Htun, A.T.; Bailey, L.J.; Millar, C.J. We are what we do: Research outputs of public health. Am. J. Prev. Med. 2008, 35, 380-385.

26. Liberati, A.; Altman, D.G.; Tetzlaff, J.; Mulrow, C.; Gøtzsche, P.C.; Ioannidis, J.P.A.; Clarke, M.; Devereaux, P.J.; Kleijnen, J.; Moher, D. The PRISMA statement for reporting systematic reviews and meta-analyses of studies that evaluate healthcare interventions: Explanation and elaboration. BMJ 2009, 339, doi:10.1136/bmj.b2700.

27. Sanson-Fisher, R.W.; Campbell, E.M.; Perkins, J.J.; Blunden, S.V.; Davis, B.B. Indigenous health research: A critical review of outputs over time. Med. J. Aust. 2006, 184, 502-505..

28. Cochrane Effective Practice and Organisation of Care Review Group. Data Collection Checklist. Available online: http://epoc.cochrane.org/sites/epoc.cochrane.org/files/uploads/ datacollectionchecklist.pdf (accessed on 7 November 2013).

29. Pan, W.; Connett, J.E. Selecting the working correlation structure in generalized estimating equations with application to the lung health study. Stat. Sinica 2002, 12, 475-490. 
30. Hawkins, N.G.; Sanson-Fisher, R.W.; Shakeshaft, A.; D’Este, C.; Green, L.W. The multiple baseline design for evaluating population-based research. Am. J. Prev. Med. 2007, 33, 162-168.

31. Sanson-Fisher, R.W.; Bonevski, B.; Green, L.W.; D’Este, C.A. Limitations of the randomised controlled trial in evaluating population-based health interventions. Am. J. Prev. Med. 2007, 33, $155-161$.

32. Stewart, J.M.; Sanson-Fisher, R.W.; Eades, S.J.; Mealing, N.M. Strategies for increasing high-quality intervention research in Aboriginal and Torres Strait Islander health: Views of leading researchers. Med. J. Aust. 2010, 192, 612-615.

33. Bonevski, B.; Randell, M.; Paul, C.; Chapman, K.; Twyman, L.; Bryant, J.; Brozek, I.; Hughes, C. Reaching the hard-to-reach: A systematic review of strategies for improving health and medical research with socially disadvantaged groups. BMC Med. Res. Methodol. 2014, 14, doi:10.1186/ 1471-2288-14-42.

34. Leeman, J.; Harrell, J.S.; Funk, S.G. Building a research program focused on vulnerable people. West. J. Nurs. Res. 2002, 24, 103-111.

35. Sanson-Fisher, R.; Brand, M.; Shakeshaft, A.; Haber, P.; Day, C.; Conigrave, K.; Mattick, R.; Lintzeris, N.; Teesson, M. Forming a national multicentre collaboration to conduct clinical trials: Increasing high-quality research in the drug and alcohol field. Drug Alcohol. Rev. 2010, 29, 469-474.

36. Pyatak, E.A.; Blanche, E.I.; Garber, S.L.; Diaz, J.; Blanchard, J.; Florindez, L.; Clark, F.A. Conducting intervention research among underserved populations: Lessons learned and recommendations for researchers. Arch. Phys. Med. Rehabil. 2013, 94, 1190-1198.

37. Bryant, J.; Bonevski, B.; Paul, C.; O’Brien, J.; Oakes, W. Delievering smoking cessation support to disadvantaged groups: A qualitative study of the potential of community welfare organisations. Health Educ. Res. 2010, 25, 979-990.

38. Cunnigham, J.A.; Kushnir, V. Could the use of biochemical validation of smoking abstinence introduce a confound into the interpretation of randomized controlled trials of tobacco cessation? Addiction 2013, 108, 826-828.

39. Noonan, D.; Jiang, Y.; Duffy, S.A. Utility of biochemical verification of tobacco cessation in the Department of Veteran Affairs. Addict. Behav. 2013, 38, 1792-1795.

40. Shipton, D.; Tappin, D.M.; Vadiveloo, T.; Crossley, J.A.; Aitken, D.A.; Chalmers, J. Reliability of self reported smoking status by pregnant women for estimating smoking prevalence: A retrospective, cross sectional study. BMJ 2009, 339, doi:10.1136/bmj.b4347.

41. West, R.; Zatonski, W.; Przewozniak, K.; Jarvis, M.J. Can we trust national smoking prevalence figures? Discrepancies between biochemically assessed and self-reported smoking rates in three countries? Cancer Epidemiol. Biomark. 2007, 16, 820-822.

42. McCambridge, J.; Witton, J.; Elbourne, D.R. Systematic review of the Hawthorne effect: New concepts are needed to study research participation effects. J. Clin. Epidemiol. 2014, 67, 267-277.

43. McCambridge, J.; Kypros, K.; Elbourne, D. In randomization we trust? There are overlooked problems in experimenting with people in behavioral intervention trials. J. Clin. Epidemiol. 2014, $67,247-253$. 
44. Higgins, J.; Green, S. Cochrane Handbook for Systematic Reviews of Interventions. Available online: http://handbook.cochrane.org/ (accessed on 3 February 2014).

45. Bryant, J.; Bonevski, B.; Paul, C.; McElduff, P.; Attia, J. A systematic review and meta-analysis of the effectiveness of behavioural smoking cessation interventions in selected disadvantaged groups. Addiction 2011, 106, 1568-1585.

46. Paul, C.; Sanson-Fisher, R.; Stewart, J.; Anderson, A.E. Being sorry is not enough: The sorry state of the evidence base for improving the health indigenous populations. Am. J. Prev. Med. 2010, 38, $566-568$.

(C) 2015 by the authors; licensee MDPI, Basel, Switzerland. This article is an open access article distributed under the terms and conditions of the Creative Commons Attribution license (http://creativecommons.org/licenses/by/4.0/). 